\title{
4 Arrangement of the Netting Area
}

\subsection{Land Habitats}

Nets should be located in places with good catching prospects along a control path of reasonable length. Some practice is needed in optimizing a new location. When beginning work on new catching-grounds, even experienced ringers may not initially succeed in this task. Do not hesitate to adjust your location when you become familiar with local bird movements. Here are some general rules, which might be helpful:

1. Decide whether the catching area coincides with a path of active diurnal movement of birds, or, alternatively, if it is an ecological island, a real island in the sea, a big lake, or isolated biotope surrounded by habitats unsuitable for a group of birds of interest (Figure 4.1). Diurnal migrants frequently fly along guiding lines like seas, riverbanks or shores, strips of bushes between forests, and so on. The same applies to many nocturnal migrants, especially during peak days, but in a less visible way; they move from one bush or tree to another.

2. Nets placed within an area of active movement must be oriented perpendicular to the main direction of movement. Nets placed at other angles will not catch optimally. At times, the stream of migrants is so narrow that the only sensible thing is to concentrate nets within this corridor. You can even locate nets one after another at an interval of around ten meters (birds can easily to be caught into the next net when flying down after missing the first one). Such peculiarities of the area will be detected during peak days of migration only. In transient locations, it is advisable to locate the nets in front of more conspicuous bushes or just behind them (or both).

3. At island-type localities, most attention should be paid to differentiation of micro-scale habitats. Locate nets between two bushes, across paths of trees and bushes, at borders between different habitats etc. (Figure 4.2). Look for berries and seeds attractive to different species as well as water pools (Figure 3.18-2) which are attractive for most birds, especially within a dry area or during a period of drought. When the area is exposed to wind, look for localities that are not exposed to these prevailing winds; the best solution is to position nets so that some nets will be always protected from the wind, irrespective of wind direction.

4. Selection of the catching locality in the Middle East and Africa countries has some specific constraints. Regarding ecological type, the site usually has an island-type character - this includes groups of bushes, commonly Tamarix sp., Nitraria sp., patches of reeds near small local water bodies, sewage farms or cultivated orchards, and olive-tree plantations. So, the general philosophy of nets distribution is as it is for island-type localities. The difference depends, however, on general geographical location - in some places we can expect only a short- 


\section{Coastal site (N-S movement)}

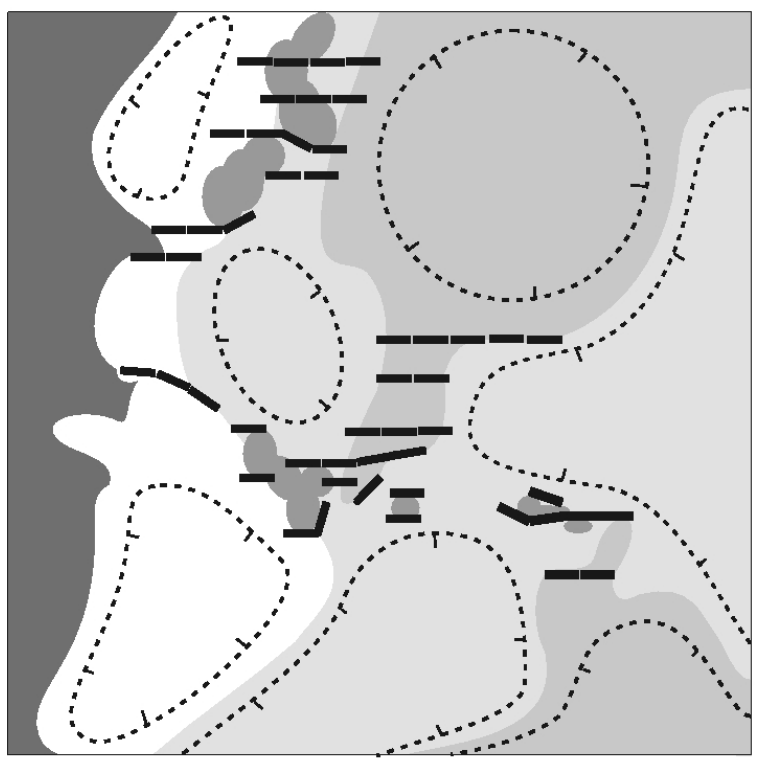

Island-type site
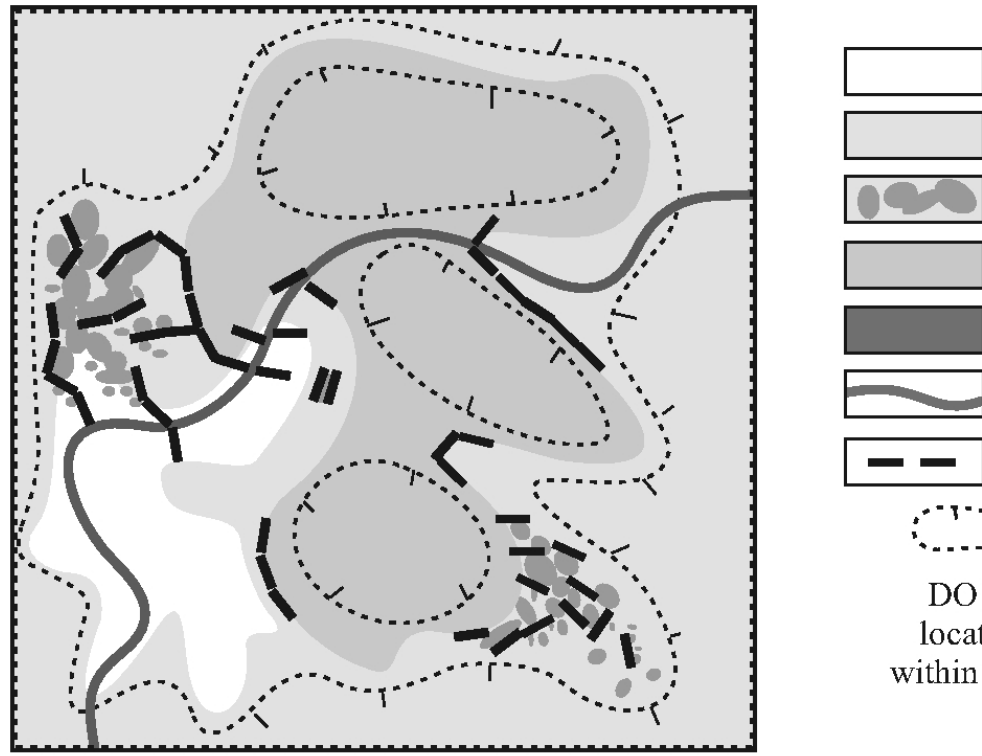

reedbed

meadow

bushes

forest
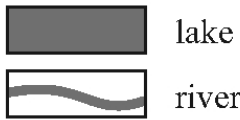

$\omega$ nets

$\because \cdots$

DO NOT

locate nets

within the area

Figure 4.1: Example of properly distributed nets in two types of sites: "coastal type" site where the coast is a guiding line for migration and "island type" site with no directional movement of birds. 


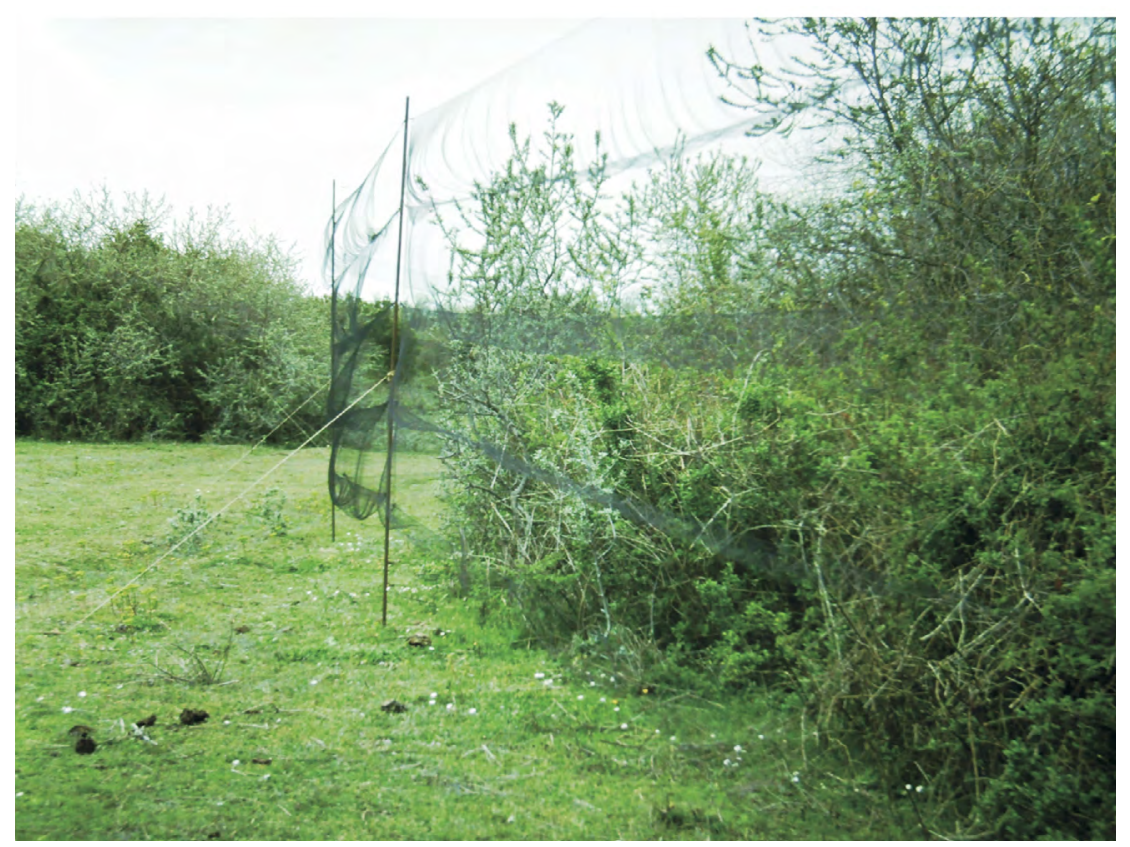

Figure 4.2-1: Typical situation of double net in front of bushes. Manyas, Turkey. Photo P. Busse.

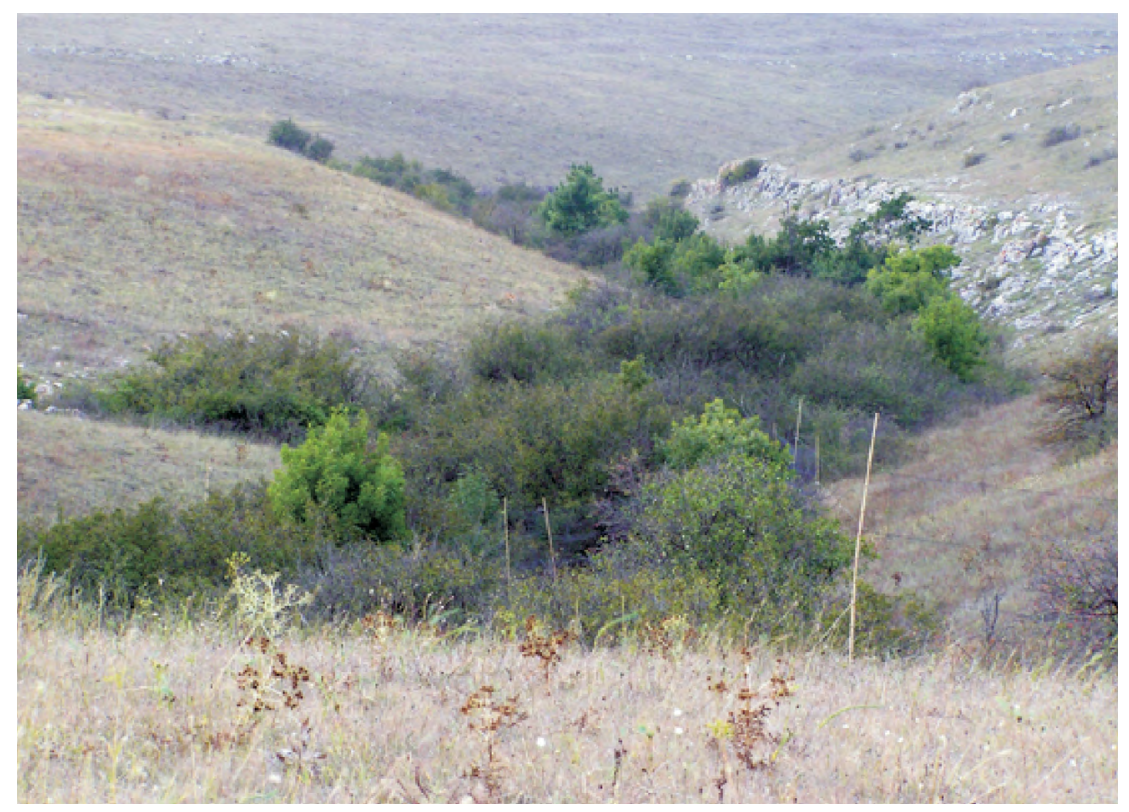

Figure 4.2-2: Location of catching area in an island of bushes at a steppe. Olenevka, Ukraine. Photo L. Maksalon. 
stop behaviour of nocturnal migrants; they land at the end of a night, stay a day and depart next evening. In such places, we can expect only one to two hours of good morning catches; the birds move around in very short time and then rest without changing place, and distribution of nets then plays less important role; there is no sense to look for feeding places. At a place where real stop-over can occur, like when birds are looking for good feeding conditions (e.g. vineyards, fig or olive plantations, and sites around drinking water available), one may find good catching prospects. Other constraints have a logistical character: living conditions, local transport, sun shelter, etc.

Nets may be used in singles or connected in rows. As a rule, single nets are more effective than the same number of nets built into rows. However, local configurations of vegetation may necessitate the use of rows instead of single nets. Rows are frequently used in more monotonous habitats, like reed beds, young tree plantations, etc. Where nets are set in long rows, a zigzag configuration is better than a straight line. Remember that nets should be easily accessible, for both birds and for ringers, from both sides, and the net should be located far enough from nearby vegetation. This allows the bird to achieve the flight speed necessary to "open" the shelf of the net, and the ringer will be able to remove the bird without entangling himself and the net in e.g. thorny bushes. When nets get entangled in e.g. alder cones or dog rose twigs, the mesh will inevitably take damage.

The length of the control path depends on the locality, number of nets, and anticipated number of staff available during peak days. Longer paths allow for a better selection of efficient netting locations, but when there are a lot of birds, the control will be too long. It is a good idea to make two or three shorter control paths controlled by different people or by one person (one after another), but always in the same order. This minimizes the potential number of caught birds after the control path, so he/she can come back to the laboratory, leave the birds, and then continue to the next path. In general, a control tour should not last more than fifteen minutes after few birds are caught. Control paths going through reed beds and marshes should be much shorter than paths in dry habitats.

Establishment of a new catching stand requires a few steps:

1. Walk around the area and carefully choose the best localities for nets. Try to look at the environment from the point of view of a migrating bird: which strip of bushes leads in the right direction for continued migration? Where would a bird hide when a raptor approaches? Where is their food and water? Consider the number of nets at hand and the expected length of the control path - should this site have one path or several?

2. Try to connect the nets selected by a path to be as short and straight as possible. Avoid steep hill slopes. Walking up and down hillsides may be harmful to the birds and to the ringer when the ground is wet, for if there is large number of birds, one may have to run along the path. If possible, avoid crossing ditches and 
places easily flooded by rainwater. Furthermore, the full surface of any net or any net row should, if possible, be visible from the control path (Figure 4.3). If this requirement is complied with, it will only be necessary to approach nets when birds are actually caught and during evening and night controls. The path may run along the nets or pass their ends, i.e. avoid crossing them perpendicularly. The continuous need to pass under the bottom net string may damage the net, and the ringer could lose time when in a hurry.

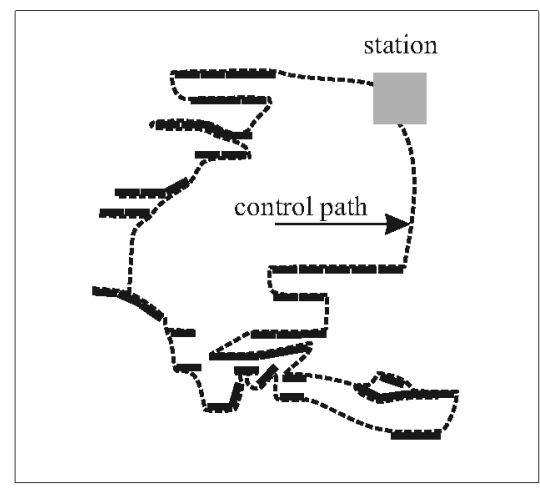

GOOD

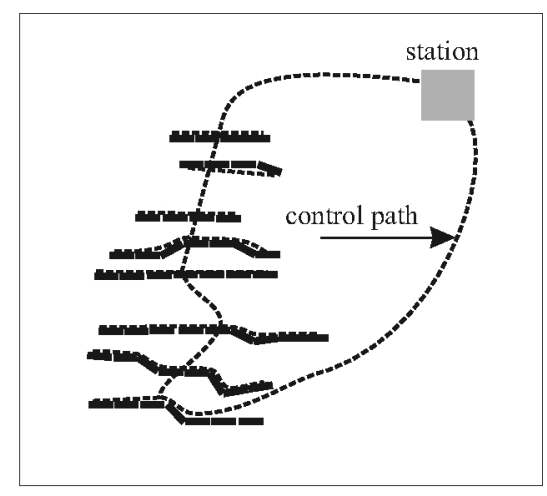

WRONG

Figure 4.3: Correctly (left) and incorrectly (right) arranged control paths.

3. Thoroughly clear up the selected sites, prepare and erect the net poles in proper places; you will save time and not have to clear nets entangled in twigs, etc. when erecting them. Also perform a preliminary clearing of the control path.

4. Erect the station laboratory stand. When the first nets have been established, you will usually have good catches of local birds; readiness for this at the station laboratory is necessary, so erect it first.

5. Erect the nets and start catching.

6. Carefully monitor the catching efficiency of nets and the behaviour of birds around them. In many cases, it will be prudent to adjust the location of nets and to correct the course of the control path. This is rule rather than exception: the human eye is not a bird's eye.

7. When net locations and the control path are thoroughly fixed, clear up both nets stands (Figure 4.4) and the whole course of the control path. Consecutive adjustments may become necessary later on when e.g. new species start to migrate. When a net is entangled in a twig or any ground plant, remove the obstacle with a clean cut (land-owners, farmers, hunters: note the traces of your activities!). Particularly, the ground under the nets must be well cleaned - birds caught in the bottom shelf should not be entangled or hidden in ground 
vegetation. This may cause their death when the weather is cold and wet, or they may be overlooked in darkness. Furthermore, for your own convenience and to save time: clear the control path. You should be able to walk along it with ease in order to avoid branches, twigs, fallen trees etc. When the ringer is in a hurry, an eye may get hurt by a twig, a leg broken over a branch, and the birds may even get killed when a bag hits the ground. And do not laugh here - this is the truth!

Starting a new season in a familiar area is much easier - you only have to clean young twigs and plants that sprouted in previously cleaned spaces.

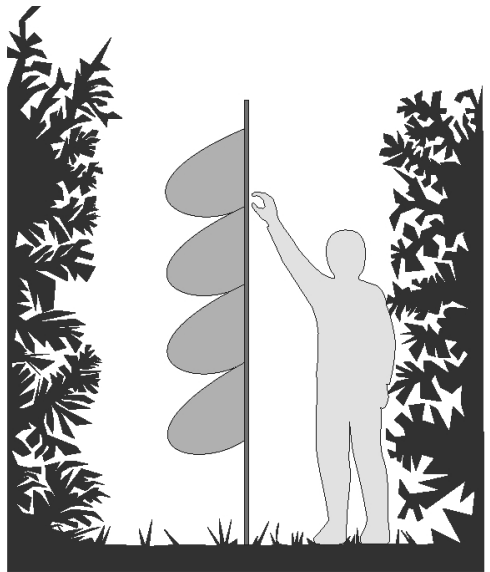

GOOD

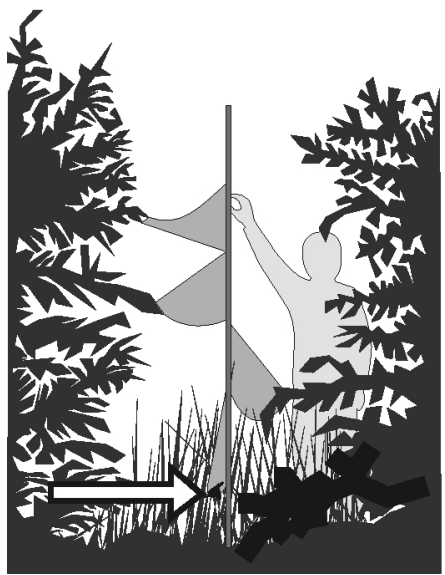

WRONG

Figure 4.4: Correctly (left) and incorrectly (right) arranged net stand. Arrow points the bird that may be overlooked.

\subsection{Wetland Habitats}

When arranging the catching area in wetland habitats, the procedure differs between pure reed beds and wetland with mixed sedge-reed-willow vegetation. A good catching opportunity is one objective, and reasonable time for control walks is another. The latter depends mainly on the quality of the ground. On permanently moist terrain, paths made of the boards fixed to wooden poles may be necessary (Figure 4.5). Where there is no possibility to use permanent paths, the speed of control walks in swampy ground covered by water will be low and the length of the path must be limited. Note that even apparently firm ground will become difficult to pass after being used a couple of times, this is particularly important to know when the path goes through standing water. The effectiveness of catching within the reed-beds differs from place 
to place. As a rule, the most effective nets are the ones located at the borders between reed and open water or bushes and trees. This border zone is the preferred habitat of the Reed Warbler. Single willow bushes attract a lot of birds, and their sides are usually good catching places. Linearly distributed (e.g. along the ditches) small bushes and trees always provide good catches; put the nets across such lines. In the core regions of monotonous reed-beds, the catching result is markedly lower. Open places with dispersed, low reeds and sedge have very low catching efficiencies. When rows of nets are erected within reed-beds, they should not be arranged as a straight line.

When nets are erected in wet habitats, their stretching and maintenance need extra attention. "Anchoring" strings attached to the end poles of a row will guarantee permanent stretching. The net should be set so high that birds caught in the lowest shelf will not get submerged in water, and the security margins must allow even for heavier birds (e.g. the Water Rail). Keep in mind that wet nets are longer than dry ones.

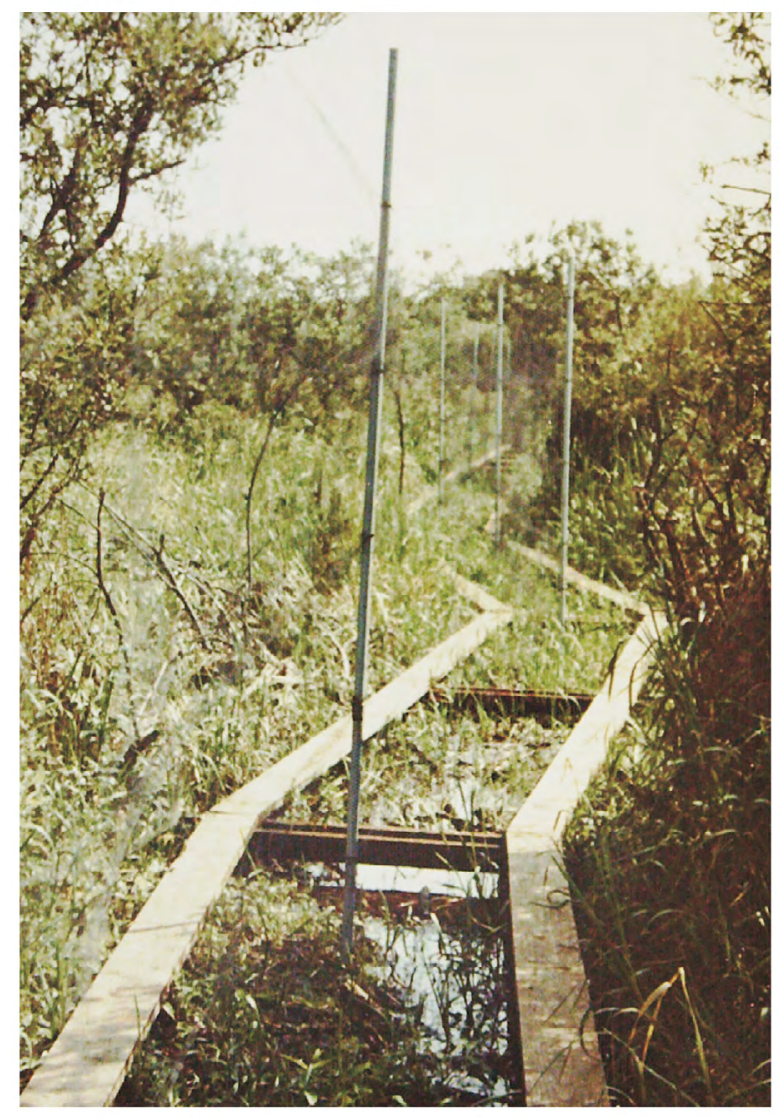

Figure 4.5-1: Comfortably arranged nets line through muddy area. Die Reit, Germany. Photo R. Lille. 


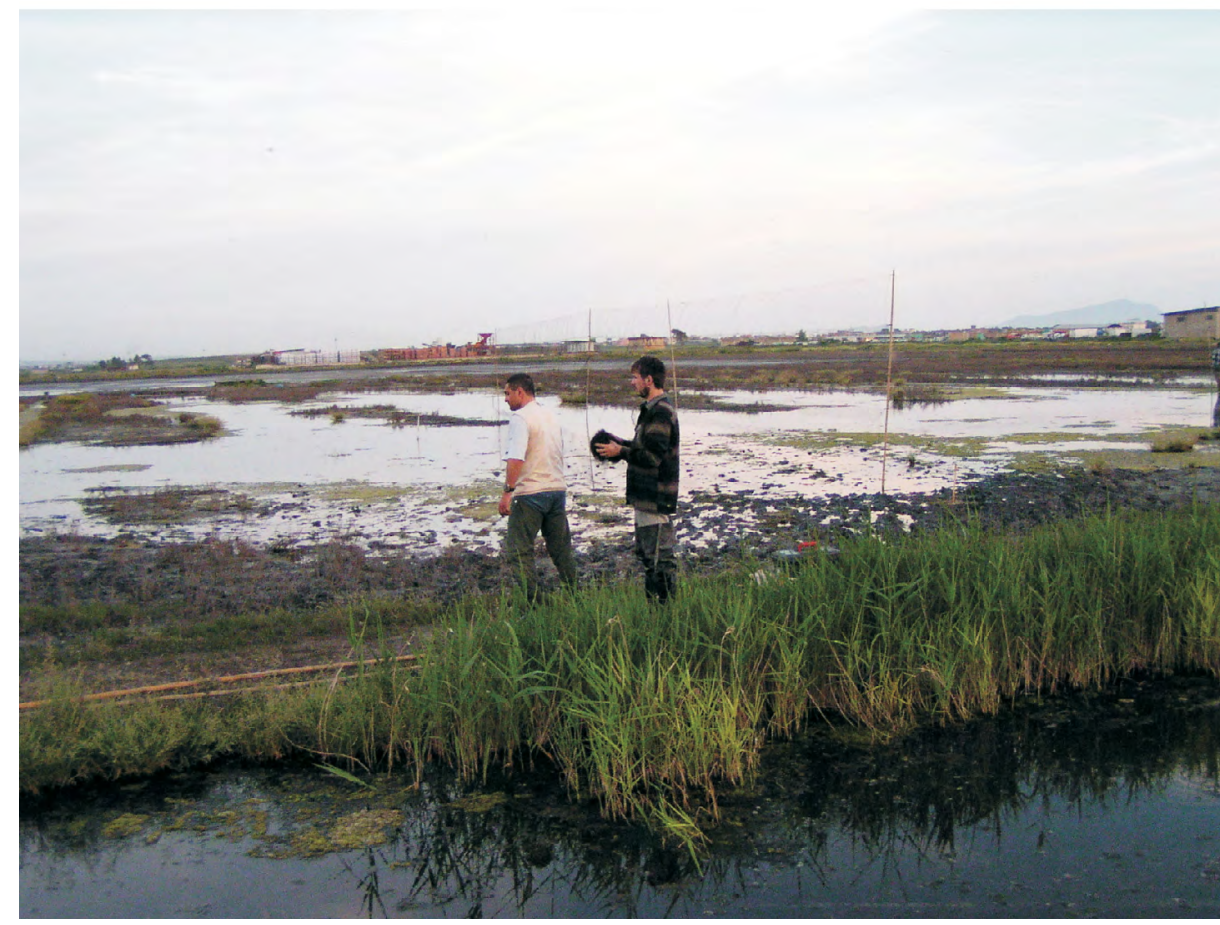

Figure 4.5-2: Setting nets for catching waders at open wet area. Volturno plain, (Caserta), Italy. Photo W. Meissner.

\subsection{Documentation of the Netting Area}

When the catching area has been arranged, basic documentation must be made. This includes mapping the area with a description of the habitats. All net locations should be indicated and numbered, independently of the custom applied: noting or not noting net numbers in a ringing documentation. A list of erected nets by numbers must be made with descriptions of the net parameters (if differentiated) and the timeframe(s) of operation. Any additional changes should be written in this document, e.g. date of removal or addition of nets. When changing the net location, give the next free number as the number of a new net, e.g. "2 Sept. net no. 4 moved to 21 ".

Apart from a general description of the catching area, which is obligatory routine, a detailed description of the net surroundings within $20 \mathrm{~m}$ on each side should be done if the intention is to make a more detailed study of habitat preferences for a special project. This should be done separately for spring and autumn seasons. 
The net location habitat coding after idea of W. Peach (Manual of Field Methods Bairlein, 1995), modified (optional):

1. Habitat type (1 letter code)

$\mathrm{R}$ - habitats with reeds

$\mathrm{S}-\mathrm{scrub}$

$\mathrm{W}$ - woodland

$\mathrm{X}$ - other

2. Habitat elements ( 2 letters code)

For habitat types R, S, W habitat details are coded:

$\mathrm{P}$ - reeds (Phragmites spp.)

$\mathrm{T}$ - reedmace (Typha spp.)

J - rushes (Juncus spp.)

C - sedges (Carex spp.)

$\mathrm{B}$ - bushes

$\mathrm{H}$ - herbs

$\mathrm{G}$ - grass

$\mathrm{L}$ - broadleaf trees

$\mathrm{F}$ - coniferous trees

Uniform habitat is coded by doubling the basic code, e.g. PP - pure reeds; mixed habitat is coded as two-letter code giving information on two dominant elements, e.g. PT - mainly reeds but with reedmace, TP - mainly reedmace, but with reeds etc.

For X coded habitat type separate two letter code:

MT - mountaintop

ND - heathland

$\mathrm{AB}$ - acid bog

FM - farmland

SM - salt marsh

$\mathrm{XX}$ - other special habitat (describe in comments)

3. Height of vegetation (1 number code)

Code average height:

0 - less than $1 \mathrm{~m}$

$1-1-2 \mathrm{~m}$

$2-2-3 m$

$3-3-6 \mathrm{~m}$

6-6-9 m

9 - more than $9 \mathrm{~m}$ 
4. Presence of water (letter/number code)

No water

NO - dry

N1 - wet

N9 - dried out (water was earlier in the season, but now dried out)

Standing water

So - depth less than $10 \mathrm{~cm}$

S1 - depth 10-30 cm

S2 - depth 30-100 cm

$\mathrm{S} 3$ - depth more than $100 \mathrm{~cm}$

Flowing water

F1 - small stream

F2 - river

5. Fruit (1 number +2 letter code)

Presence of fruits

0 - no fruit

1 - some fruit

2 - much fruit

Type of fruit

Every fruit has two-letter code - list two commonest ones; when more than two code MX; when unknown - code XX.

JU - Juniper (Juniperus spp.)

TA - Yew (Taxus spp.)

IL - Holly (Ilex spp.)

EU - Spindle (Euonymus spp.)

RH - Buckthorn (Rhamnus catharticus, Frangula alnus)

RU - Brambles (Rubus spp., includes raspberry, blackberry, strawberry)

RO - Roses (Rosa spp., includes dog rose and sweet briar)

PR - Cherries and plums (Prunus spp., includes blackthorn, wild cherry)

CR - Hawthorn (Crategus spp.)

SS - Sorbus shrubs (Sorbus spp., includes rowan, whitebeam)

RI - Gooseberry family (Ribes spp., includes blackcurrant and redcurrant)

HI - Sea Buckthorn (Hippophae rhamnoides)

VI - Mistletoe (Viscum album)

AS - Strawberry Tree (Arbutus unedo and Rhododendron shrubs)

AE - Ivy (Aralieceae family like Hedera helix)

OL - Olive family (includes Ligustrum vulgare and cultivated Olea europaea)

SM - Nightshades (Solanum spp., includes S. nigrum and S. dulcamara) 
CA - Honeysuckle fam. (Caprifoliaceae incl. Sambucus spp., Viburnum spp., Lonicera spp.)

SA - Salvadora spp.

NI - Nitraria spp.

6. Habitat management (1 letter code)

$\mathrm{O}$ - no management

$\mathrm{N}$ - normal forestry/farming management

$\mathrm{R}$ - main vegetation completely cut back at least once per year (e.g. burning or reed cutting)

C - coppicing

G - grazing

M - artificially managed (e.g. for monitoring purposes)

$\mathrm{X}$ - not known

For easier reading groups of codes can be separated by dots, e.g. S.BH3S1.1RUSO.O 